\title{
TREINTA AÑOS DE AFIANZAMIENTO DE LOS DERECHOS FUNDAMENTALES
}

\author{
Lorenzo Martín-Retortillo Baquer \\ Catedrático de Derecho Administrativo \\ Universidad Complutense de Madrid
}

\begin{abstract}
RESUMEN
El artículo describe la profunda modificación que ha representado para el sistema español de derechos fundamentales la incidencia de las instancias europeas, ante todo la Unión Europea, pero no menos el Convenio Europeo de Derechos Humanos así como la fuerza ampliatoria de la jurisprudencia del Tribunal Europeo de Derechos Humanos.

Palabras clave: Carta de Derechos Fundamentales de la Unión Europea; Convenio Europeo de Derechos Humanos; derechos fundamentales; derechos humanos; título primero de la Constitución española de 1978.
\end{abstract}

\begin{abstract}
The article describes the deep change that has represented for the Spanish system of fundamental rights the impact of the European institutions, primarily the European Union, but not least the European Convention on Human Rights as well as the expanded power of the European Court of Human rights.

Key words: European Convention on Human Rights; First Title of the Spanish Constitution; human rights; the European Union's Charter on Human Rights.
\end{abstract}


1.- Una de las realizaciones más destacadas de la «transición política», que nos llenó de satisfacción a quienes la vivíamos de cerca — aunque no sé si siempre habrán caído en la cuenta muchos de quienes vinieron después y se encontraron con todo dado-, fue que España volviera a recuperar la posición que le correspondía en el concierto de las naciones europeas. La feliz oportunidad que algunos habíamos tenido de viajar al extranjero nos había permitido contrastar bien a las claras el sistema de coto cerrado y aislado en que se había situado España en el anterior periodo político, tan lejos de la vitalidad y de la intensa y gratificante red de relaciones que se vivía en las naciones de nuestro entorno. De ahí la profunda emoción e ilusión con que, una vez desaparecido el General, se fueron viviendo los sucesivos y continuados pasos de adaptación de nuestro sistema, de apertura al exterior, y de integración, con todo lo que representaba. Los «Pactos de la Moncloa», con admirable confluencia de tan variadas fuerzas, trajeron, entre otras cosas, aparte de muy destacados acuerdos económicos y sociales, la derogación de un paquete importante de normas, armazón del viejo sistema que se quería superar. Fueron muchos los pasos que se fueron dando en un tiempo récord, no pocos de ellos relacionados con los derechos humanos, objeto principal de la presente reflexión: ingreso en el Consejo de Europa, firma y ratificación del Convenio para la Protección de los Derechos Humanos y de las Libertades Fundamentales hecho en Roma el 4 de noviembre de 1950, que solemos llamar el Convenio Europeo, o, simplemente, el Convenio; algo más tarde, admisión, adelantándonos incluso a Francia, de la entonces existente reclamación individual, lo que representaba el pleno ingreso en el sistema del Tribunal Europeo de Derechos Humanos -o Tribunal de Estrasburgo, dada la ciudad francesa en que tiene su sede-, en una época en que todavía existía la Comisión Europea de Derechos Humanos como paso previo; el nombramiento como juez del Tribunal de uno de nuestros más destacados juristas, el profesor Eduardo García de Enterría, así como la propuesta para la Comisión Europea de Derechos Humanos de persona tan destacada como el profesor Juan Antonio Carrillo Salcedo; la firma y ratificación de los dos pactos de Nueva York de 1946, el de Derechos Civiles y Políticos, y el de Derechos Económicos, Sociales y Culturales; y en esta dirección, la sucesiva participación de pleno derecho en una muy larga lista de tratados y convenios internacionales contemplando aspectos concretos referentes a los derechos humanos, como la Carta Social Europea, la Convención contra la Discriminación de la Mujer, Libertad Sindical y Protección del Derecho de Sindicación, y un muy largo etcétera. 
2.- Desde otra perspectiva, una de las aspiraciones más sentidas en aquellas circunstancias era la del ingreso en lo que entonces se llamaba la Comunidad Económica Europea, la actual Unión Europea, cuya puerta había estado cerrada dadas las características y carencias del régimen político anterior. Aparte del ingente proceso de aproximación que representaría en su conjunto la Constitución de 1978, es de destacar en ella la incisiva y tan amplia previsión del artículo 93 abriendo, de una manera muy generosa, la posibilidad de atribuir el ejercicio de competencias derivadas de la Constitución a una organización o institución internacional, amplia fórmula con la que, aparte de otras posibilidades, se abría la puerta para facilitar el ingreso en la Comunidad Económica Europea, sabiendo todo lo que podía representar de cesión de nuestras competencias. Conscientes de que «renuncias» tales era algo que se deseaba vivamente, con un sentimiento muy difundido entre la población y que, además, suscitaba el apoyo unánime de las fuerzas políticas más representativas, sin que faltaran las minorías opuestas.

Destacaré también, desde otra perspectiva, una interesante aportación de la Constitución de 1978 en lo referente a la virtualidad de los derechos humanos, cuando, con certera clarividencia, el artículo 10.2 dispone que aquellos «se interpretarán de conformidad con la Declaración Universal de Derechos Humanos y los tratados y acuerdos internacionales sobre las mismas materias ratificados por España». De este modo, el sistema español se vinculaba con el prestigioso panorama internacional de los derechos fundamentales.

3.- Toda esa metodología - la Comunidad Económica Europea, por supuesto, pero también las anteriores referencias al Convenio Europeo y demás- abría la puerta a una consistente operación de recepción de normas y fórmulas ajenas, que habrían de insertarse en nuestro sistema jurídico con carácter preferente, desplazando nuestras soluciones propias. Me gustó hablar en la ocasión de «interconexión de los ordenamientos jurídicos», observando que soluciones venidas de lejos iban a desplazar con entera normalidad a las fórmulas aquí elaboradas.

4.- Resultó grato destacar en un trabajo temprano cómo el Tribunal Constitucional iba recibiendo con atención, al decidir sus asuntos sobre derechos fundamentales, las líneas marcadas por la jurisprudencia del Tribunal Europeo de Derechos Humanos, metodología que habrían de ir asumiendo, si bien de forma más pausada, el conjunto de tribunales y jueces integrados en el Poder Judicial, con lo que se iría produciendo sucesivamente el necesario ensamblamiento. Lo que me lleva a formular cuanto antes una observación previa, que juzgo interesante. 
Si se trata de reflexionar ahora sobre el influjo que el derecho español ha recibido de la Unión Europea en lo concerniente a los derechos humanos, hay que observar que, en sus orígenes, la Comunidad Económica Europea se va a preocupar fundamentalmente de los aspectos económicos, comerciales y de mercado, una vez que se reconoce la garantía de las famosas libertades comunitarias: libre circulación de personas, de servicios, de mercancías y de capitales, así como la libertad de establecimiento. Del resto, era escasa la atención que en los inicios se dedicaría a los derechos humanos. Se ha destacado sobradamente este fenómeno -así, entre otros muchos, J. A. Carrillo, Ricardo Alonso, yo mismo-, así como que el Tribunal de Justicia iría dando entrada progresivamente a derechos fundamentales, desde la metodología de principios generales del derecho deducidos de las tradiciones constitucionales de los Estados miembros. Poca oferta en la materia desde la CEE, podríamos decir, muy activo, en cambio, el Tribunal de Estrasburgo en cuanto al ámbito concreto del Convenio Europeo. Pero la Unión Europea no dejaría de ir evolucionando, en un proceso duradero y pausado, marcado, como todo en la historia de la UE, por las singularidades y aspiraciones de los Estados miembros. Yo mismo, entre otros muchos, he dedicado atención a este largo proceso, que alcanzaría un punto destacado al redactarse en 2000 una moderna declaración de derechos propia, la Carta de Derechos Fundamentales de la Unión Europea, que designaremos como "la Carta», y que encontraría su culminación por el momento, cuando el Tratado de Lisboa, entrado en vigor el 1 de diciembre de 2009, le otorgaría «el mismo valor jurídico que los Tratados» (artículo 6.1 del Tratado de la Unión Europea, en adelante, TUE). Debiendo recordar que el propio precepto exige que a la hora de su interpretación y aplicación se tengan en cuenta las «explicaciones» elaboradas por el Presídium de la Convención que redactó la Carta, en las que se puntualiza el origen de cada precepto.

Es así como en el ámbito de los derechos humanos nos vamos a encontrar los españoles — como el resto de los Estados comunitarios, cada uno con sus peculiaridades - con tres distintas fuentes, por más que se hallen íntimamente relacionadas y con influencias recíprocas. Está, ante todo, el viejo Convenio Europeo, completado intermitentemente por los sucesivos Protocolos Adicionales, pero no menos por el tono intensamente evolutivo que el Tribunal de Estrasburgo ha dado a su jurisprudencia. Me ha gustado hablar al respecto de su metodología de «defensa cruzada de derechos», en el sentido de que, por ejemplo, el medio ambiente no estará en la lista de derechos y libertades garantizados por el Convenio de Roma y, sin embargo, el Tribunal consigue con 
frecuencia muy eficaz defensa apoyándose en otros títulos que sí están reconocidos, como el derecho a la intimidad, el derecho de propiedad o el derecho a la protección jurisdiccional, entre otros. De modo que, indudable metodología aperturista y expansiva. Pues bien, este sistema, básico y bien asentado, tan activo como presente, influiría decididamente cuando se redactan los dos pasos que menciono a continuación.

Hay que aludir, en segundo lugar, al importante conjunto que encierra el título primero de la Constitución de 1978, «De los derechos y deberes fundamentales». Se ofrece así en el derecho español un importante tronco de derechos fundamentales, para cuya elaboración, insisto, se tuvo muy en cuenta el Convenio Europeo, si bien se completaría con aspectos que éste no había previsto.

Pero también incide en España, en tercer lugar, el importante núcleo de derechos fundamentales disperso a lo largo de los tratados de la Unión Europea, desarrollado a su vez en el derecho derivado y hoy codificado en lo esencial en la Carta de Derechos Fundamentales de la Unión Europea, que al final, como se dijo, ha logrado vigencia plena, y a la que el Tribunal de Luxemburgo está dedicando atención muy destacada. Sin olvidar que, por el momento, y sin perjuicio de posibles avances en el futuro, el Convenio Europeo de Derechos Humanos no sólo ha influenciado directamente la presencia de los derechos fundamentales en el ámbito de la Unión Europea, del mismo modo que no pocos artículos de la Carta siguen casi literalmente lo que dicen los preceptos del Convenio Europeo, sino que los Tratados de la Unión se reclaman directamente a éste de manera inequívoca y reiterada. Así, el artículo 6.3 TUE, preámbulo de la Carta (párrafo quinto) o, en el articulado de ésta, de forma inequívoca, los artículos 52.3 y 53.

Reflexionando acerca de las tres fuentes, se puede afirmar que entre ellas se da una curiosa interrelación, que actúa con diversos matices. Como se decía, la más antigua de las piezas influyó decisivamente sobre las otras dos más recientes. Es algo conocido que al redactarse el título primero de la Constitución de 1978 se tuvo muy en cuenta el Convenio Europeo y sus protocolos. Por su parte, la Carta sigue muy de cerca la redacción del convenio, casi literalmente en algunos de sus preceptos, como acreditan las «explicaciones» que la acompañan, e incluso algún precepto de aquélla proviene directamente de la jurisprudencia del Tribunal de Derechos Humanos. Se ha destacado también cómo el sistema de derechos fundamentales de la Unión Europea se ha enriquecido de las «tradiciones constitucionales de los Estados miembros» a través del activismo del Tribunal de Justicia, lo que se reconoce incluso en el propio preámbulo de la Carta así como en las «explicaciones». Desde 
otra perspectiva es de recordar que el Tribunal Europeo de Derechos Humanos (TEDH), en no pocos casos, al tener que resolver un asunto, antes de alumbrar una respuesta propia, buscará si hay una solución consolidada entre los diversos países que integran el Consejo de Europa.

5.- Desde otra perspectiva, no se puede olvidar que las dos reformas expresas que han afectado a la Constitución de 1978 se han llevado a cabo precisamente para adecuarse al sistema europeo. Primero, y estrechamente relacionado con el ámbito de los derechos fundamentales, fue la concreta modificación del artículo 13.2, introducida en 1992, precisamente para adecuar la Constitución a las exigencias del Tratado de la Unión Europea, el hecho en Maastricht en 1992, al objeto de facilitar el derecho de sufragio pasivo a los ciudadanos de la Unión en las elecciones municipales. Más recientemente, en 2011, se reforma el artículo 135, en línea con las exigencias comunitarias, para «garantizar el principio de estabilidad presupuestaria, vinculando a todas las Administraciones Públicas en su consecución», como se dice en la exposición de motivos de la reforma. En la que, por cierto, se recalca cómo la estabilidad presupuestaria resulta decisiva para el mantenimiento y desarrollo del Estado social de derecho "y en definitiva para la prosperidad presente y futura de los ciudadanos». Lo que, indudablemente, también la vincula con la efectividad de los derechos fundamentales: sin una financiación adecuada los derechos fundamentales pierden la mayor parte de su eficacia. Por cierto que frente a la opinión que algunos se han empecinado en difundir erróneamente de la falta de puesta al día de la Constitución, en ambas ocasiones, dado que se consideró necesaria y oportuna la reforma, ésta se llevó a cabo con toda normalidad y sin ningún problema.

Dato este muy importante, el de que de una manera expresa las exigencias comunitarias llevaran directamente a una reforma de la Constitución. Reforma directa e inequívoca, insisto. Enseguida recalcaré en qué gran medida el derecho comunitario incide en la aplicación de no pocas reglas constitucionales referentes a derechos fundamentales. Pero no dejaré pasar la ocasión sin recordar cómo me gusta destacar que, sin tocarse el texto de la Constitución, y en aplicación de lo que la misma prevé en el artículo 93, los sucesivos pasos de integración en la CEE-UE, y cada vez que ésta aumentaba opciones, competencias o prerrogativas, se producía una notable mutación constitucional de nuestro sistema.

6.- Todo lo anterior me lleva a considerar que en nuestro tiempo los derechos fundamentales constituyen una amplia corona que preside tanto el sistema jurídico español como el de la Unión Europea. De modo que más allá de las peculiaridades de las fuentes del derecho, los derechos fundamentales, en cuanto valores positivizados como normas, van 
a predeterminar todo el ordenamiento, como se deduce por ejemplo tanto del artículo primero de la Constitución, que proclama como valores superiores del ordenamiento jurídico la libertad, la justicia, la igualdad y el pluralismo político, como del artículo 10.1, que abre el importante título primero, al determinar que: «La dignidad de la persona, los derechos inviolables que le son inherentes, el libre desarrollo de la personalidad, el respeto a la ley y a los derechos de los demás son fundamento del orden político y de la paz social».

En cuanto a la Unión Europea se refiere, son determinantes los basamentos establecidos, entre otros, en preceptos como el artículo 2 TUE, al disponer que: "La Unión se fundamenta en los valores de respeto de la dignidad humana, libertad, democracia, igualdad, Estado de derecho y respeto de los derechos humanos incluidos los derechos de las personas perteneciente a minorías. Estos valores son comunes a los Estados miembros en una sociedad caracterizada por el pluralismo, la no discriminación, la tolerancia, la justicia, la solidaridad y la igualdad entre mujeres y hombres». Junto a estos enunciados con vocación de generalidad, desde la perspectiva de alguno de los derechos concretos, resulta muy interesante la metodología que se ofrece, por ejemplo, en el artículo 11 del Tratado de Funcionamiento de la Unión Europea (TFUE) — que no hace sino retomar anteriores formulaciones-, cuando dispone que: «Las exigencias de la protección del medio ambiente deberán integrarse en la definición y en la realización de las políticas y acciones de la Unión, en particular con objeto de fomentar un desarrollo sostenible». Es decir, presencia indiscutible del derecho fundamental a la hora de definir todo tipo de políticas.

7.- La señalada confluencia de ordenamientos, el dato de que a veces se regulan unas mismas figuras o instituciones pero con diversos matices o variantes, va a dar lugar a interesantes conflictos jurídicos, a la hora de determinar a quién corresponde dictar la disposición que se imponga, si a la instancia nacional —el juez ordinario y, en su caso, el Tribunal Supremo o el Tribunal Constitucional_-, o a la instancia europea, en lo que habrá de desempeñar un destacado protagonismo la cláusula de llamada a la resolución del posible conflicto. Lo que nos sitúa, en el ámbito interno, ante la «cuestión de inconstitucionalidad», del artículo 163 de la Constitución —el órgano judicial se remite al Tribunal Constitucional—, y en el ámbito europeo ante la «cuestión» del artículo 267 TFUE —el órgano judicial, o incluso el Tribunal Constitucional se dirige al Tribunal de Justicia.

Testimonial resulta al respecto el reciente asunto Melloni, primera cuestión planteada por el Tribunal Constitucional español ante el Tribu- 
nal de Justicia, que ha logrado cambiar el sentido de la jurisprudencia nacional y que ha dado lugar a sustanciosos comentarios entre nosotros (Xavier Arzoz, Ricardo Alonso García, entre otros). En la problemática que se viene aludiendo, se ofrece incluso la alternativa de la posible compatibilidad en un mismo asunto de la cuestión ante el Tribunal Constitucional y de la cuestión ante el Tribunal de Justicia. Sin especular ahora acerca de lo que podría suceder si la Unión Europea asume de lleno el Convenio Europeo, en la hipótesis incluso de que entre en vigor el Protocolo 16 al citado Convenio, y el Tribunal señalado pudiera plantear la cuestión ante el Tribunal Europeo de Derechos Humanos. Ello incluso sin dejar de contar con las reticencias de algún Tribunal Constitucional, celoso de defender su fuero para proteger su sistema de derechos fundamentales o su identidad nacional, en línea con lo que enseguida se recordará, y de lo que podría ser testimonio significativo la reciente sentencia del Bundesverfassungsgericht, de 15 de diciembre de 2015 (sobre lo anterior, muy útiles las reflexiones desarrolladas en la sesión de 25 de mayo de 2016, del «Seminario García de Enterría», con ponencia a cargo de Ricardo Alonso García, Juan Ignacio Ugartemendía Eceizabarrena y Xavier Arzoz). El sistema jurídico se complica a pasos agigantados, pudiendo afectar a la correcta aplicación del derecho, que reclama simplicidad y claridad, como no se cuiden con diligencia y aplicación las exigencias necesarias para el correcto acabado de las normas y como no reaccionen con energía y solidez los órganos jurisdiccionales responsables.

8.- La relación entre el derecho interno y el derecho europeo, con la idea de primacía de este último, no ha dejado de plantear en algunos momentos un tenso problema que ha atraído la atención de los estudiosos. Normal, en principio, al margen del esfuerzo que supone, que con carácter general se afirme la primacía del derecho europeo. El problema aparece cuando se pudiera poner en cuestión el destacado elenco de derechos fundamentales, ardua y laboriosamente conseguidos, recogido en la Constitución del concreto Estado. ¿Podría ser desconocido e, incluso, derrotado, por un derecho europeo insensible a esos valores cualificados? No se olvide que, como antes se dijo, hubo un largo periodo en el que la Comisión Económica Europea o, incluso, la Unión Europea luego, carecía de un conjunto sólido de derechos fundamentales. Es sobradamente conocida la reacción de la Corte Costituzionale, o del Bundesverfassungsgericht, a las que ahora me remito. Hoy el panorama cambia sustancialmente dado que al fin se alcanzó la Carta de Derechos Fundamentales, homologable, en general, con las previsiones de los Estados miembros. De todas maneras, tales viejos ejemplos son 
buen testimonio de una problemática que pudiera volver a florecer si se diera la ocasión, a la par que es expresión de una activa postura de autoafirmación de algunos Estados.

De todas maneras, es curiosa la efectiva incidencia que el derecho comunitario puede tener, de manera directa o indirecta, sobre el texto o la aplicación de la Constitución, de manera especial cuando se trate de «potenciar» las opciones de los ciudadanos. En otras ocasiones se ha podido observar la reticencia de Alemania para con el derecho europeo, pero a veces las cosas están muy claras y el comportamiento puede resultar modélico. En otro lugar he estudiado, y ahora me remito globalmente a ello, un interesante episodio concerniente a la discriminación por razón de sexo, tema que ha sido siempre uno de los caballos de batalla de la CEE-UE, como bien se deduce incluso de alguno de los textos que antes he transcrito. El primitivo artículo 10 de la Constitución alemana -la Ley Fundamental de Bonn-, prohibía expresamente que en las fuerzas armadas las mujeres tuvieran acceso a los servicios con armas, lo que significaba que no podían acceder a puestos cualificados. El Tribunal de Justicia entendería que tal discriminación era incompatible con el derecho comunitario. Y Alemania, diligentemente y de forma inmediata, modificó el texto constitucional para adaptarlo al derecho comunitario.

Ello me lleva a destacar una curiosa incidencia del derecho europeo sobre nuestra Constitución. Según el dictado literal del texto del artículo 15, la abolición de la pena de muerte no es completa, dado que se establece la reserva de «lo que puedan disponer las leyes penales militares para tiempos de guerra». España reaccionó pronto y «las leyes penales militares» hicieron desaparecer dicha opción. Pero, no cabe duda de que, en principio, según el texto de la Constitución, podría ser reactivada eventualmente la alternativa. Pues bien, hoy ya no se da tal oportunidad por virtud del derecho europeo. El artículo 2.2 de la Carta (del 2000, recuérdese) prohíbe especialmente de manera genérica y sin excepciones la pena de muerte. Y más precisamente, sin que quepa duda alguna acerca de su virtualidad, el Protocolo Trece al Convenio de Roma, hecho en Vilna en 2002, ratificado por casi todos los países del Consejo de Europa, y desde luego por España, prohíbe de manera absoluta la pena de muerte, sin que quepa ningún tipo de excepción o reserva. De modo que, a través de esta vía europea, el precepto de la Constitución contemplado, ha quedado incidido de manera determinante.

9.- Pero más allá de lo que con carácter general suponen las referencias que se acaban de mencionar, es indudable que las fórmulas y soluciones europeas han incidido de lleno en no pocas respuestas y si- 
tuaciones del derecho español. Diría, incluso, que ha marcado una ingente movilización, añadiendo, incorporando, pero también, de modo especial, desarrollando lo ya existente.

Por comenzar con un ejemplo sobresaliente, paradójico ha resultado lo que ha sucedido con el derecho al medio ambiente. Cierto que la Constitución contiene una previsión destacada al respecto, pero ello no obsta a que haya sido decisiva la influencia del derecho de la Unión en su desarrollo y potenciamiento. Es curioso que la Carta ofrece un precepto muy escueto, muy abierto aparentemente y por lo mismo lleno de posibilidades. De hecho, ha resultado enorme el papel que ha pasado a desempeñar el derecho derivado. Hasta el punto de que me gusta exclamar: ¡Qué hubiera sido de nuestro medio ambiente a no ser por la influencia y presencia del derecho comunitario! En un derecho - «derecho a disfrutar del medio ambiente adecuado", como dice el artículo 45 de la Constitución española-, que se desdobla en una enorme pluralidad de facetas, ha resultado ingente la incidencia del derecho europeo, sin olvidar el activismo que mantiene el Tribunal Europeo de Derechos Humanos que, aun sin que figure el medio ambiente en la lista del Convenio Europeo, ha sabido proyectar su presencia, a través de lo que me gusta llamar, como se dijo, "defensa cruzada de derechos». Constantemente están apareciendo en su jurisprudencia nuevos testimonios de lo que digo, como bien ha acreditado Omar Bouazza Ariño. Por simplificar la referencia recordaré sólo dos casos especialmente significativos que afectaban directamente a España, el supuesto "López Ostra», de 9 de diciembre de 1994, y la Sentencia Moreno Gómez, de 11 de noviembre de 2004, sobre tema tan menesteroso como es el del ruido en las ciudades a causa del ocio nocturno. Pero volviendo al sistema de la Unión Europea, hay que resaltar el sobresaliente efecto, a través normalmente de la correspondiente directiva, en tantos sectores, así sobre el régimen de las aguas en sus más variados aspectos, los residuos y vertidos, la actuación minera e industrial, la técnica de la previsión del impacto, la información ambiental, la limpieza del aire y la protección del suelo, la responsabilidad medioambiental, la conservación de la fauna, la prevención de la contaminación, la emisión de gases de efecto invernadero, así como todo lo referente al ambiente sonoro, con la gran lacra española en lo que concierne al ruido. No insistiré más dado que en otro de los trabajos de este número se estudia específicamente el medio ambiente. Pero no podía pasar por alto tan importante contribución en esta reflexión general sobre los derechos fundamentales.

10.- Similar paralelismo puede observarse en relación con el derecho de los consumidores a su protección. También es escueto lo que dice la 
Carta, cuando en el artículo 38, bajo el rótulo «Protección de los consumidores», establece simplemente: «En las políticas de la Unión se garantizará un nivel elevado de protección de los consumidores». Lo que no es sino una vieja aspiración enraizada en las pretensiones de la CEE, y hoy reflejada en el artículo 169.1 del TFUE. La Constitución de 1978 dedicó al tema el artículo 51, incidiendo en materia sobre la que estaba muy sensibilizada la opinión pública, tras los desastres causados por la comercialización de algunos productos que no habían sido controlados suficientemente. Pues bien, hoy se cuenta con una ingente legislación en la materia, dado que a la iniciativa propia se ha sumado en el ámbito comunitario el acicate de señaladas actuaciones del Consejo, del Parlamento Europeo y de la Comisión, así como numerosas directivas y reglamentos, incidiendo en los numerosos aspectos que tienen que ver con la protección de los consumidores dada la variedad de facetas que ésta ofrece. Recuerdo personalmente la grata impresión inicial de que gracias a la legislación comunitaria pudiéramos conocer con facilidad la fecha de caducidad de los productos: para las conservas enlatadas se utilizaba un endiablado sistema de letras que no había quien lo desentrañara. Hay que ver la ventaja de que se pudiera leer con sencillez la indicación expresa de la fecha. Pues bien, a partir de ahí son casi inconmensurables los aspectos que abarca la legislación sobre protección de los consumidores. El derecho derivado cubre un sinfín de facetas que luego se han ido recibiendo en el derecho interno. Recordemos algunas de las más destacadas: embalaje y etiquetado de sustancias peligrosas, sustancias y preparados químicos, plaguicidas en las frutas y hortalizas, aditivos alimentarios, ingredientes alimentarios con propiedades aromatizantes, relación entre titulares y emisores de tarjetas de crédito, identificación del lote al que pertenece un artículo alimenticio, preparados para lactantes, alimentos dietéticos destinados a usos médicos especiales, comercialización de productos fitosanitarios, etiquetado de productos, servicio universal y derechos de los usuarios en relación con las redes y los servicios de comunicaciones electrónicas, tratamiento de datos personales y protección de la intimidad, requisitos generales de la legislación alimentaria, envases y residuos de envases, indicación de los precios de los productos, comercio electrónico, y así un muy largo etcétera.

11.- Los dos testimonios que acabo de recoger me parecen ejemplos sobresalientes de cómo el sistema europeo contribuye a potenciar la efectividad de dos derechos tan sobresalientes y tan apreciados hoy, como el derecho al medio ambiente y el derecho de los consumidores a su protección. Se comprende que el profundizar en esta tarea nos llevaría muy lejos, pero dado que el objeto de las presentes reflexiones es tan 
sólo ofrecer una visión de conjunto, no insisto más sobre ambas opciones y pasaré a mencionar de forma somera algunos testimonios de cómo el derecho europeo potencia, de tan variadas formas, el alcance real de los derechos fundamentales de nuestro sistema constitucional.

Pero antes de ello, querría ocuparme de otra línea metodológica bien interesante que me lleva a las aportaciones codificadas en la Carta - que indudablemente provienen en general de los Tratados-, y que no están en nuestra declaración de derechos propia, es decir, la ofrecida en el título primero de la Constitución. La formalización como derechos fundamentales que representa, va a suponer que nuestro acervo jurídico propio se incremente con nuevos derechos fundamentales, como tal categoría, con todo lo que representa. Sin perjuicio de que como muchos de sus contenidos ya estaban en los Tratados, y habían sido objeto de las correspondientes directivas o reglamentos, el ordenamiento jurídico español había tenido oportunidad de ir dando algunas respuestas incorporando las soluciones contempladas. Con lo cual el contenido de esos derechos fundamentales ya había comenzado a ser operativo en el sistema español.

a) El artículo 41 de la Carta, de forma un tanto sorprendente, eleva a la categoría de derecho fundamental el «derecho a una buena administración». En las «explicaciones» se reconoce que se trata de un derecho de origen jurisprudencial, desarrollado como principio general tanto por el Tribunal de Justicia como por el Tribunal de Primera Instancia. Si se pone empeño en impedir la «mala administración», una de las alternativas para la cual se llama al «Defensor del Pueblo Europeo», contemplado en el artículo 43, no extrañará que se haga todo lo posible por fomentar la «buena administración». Sin duda, el nuevo derecho quiere venir a echar una mano al angustiado ciudadano de nuestra época perdido en las redes burocráticas. En puridad, el nuevo derecho ya aparecía esparcido en las buenas leyes de procedimiento administrativo, en cuanto se desdobla en una serie de opciones garantistas algunas ya previstas, pero la elevación al rango de derecho fundamental viene a reforzar las posibilidades y constituye una notable llamada de atención para autoridades y administradores, pero también para los órganos jurisdiccionales. Sorprende el interés que el nuevo derecho ha suscitado en la doctrina (Juli Ponce, yo mismo, entre otros muchos), así como la diligencia del legislador autonómico para llevarlo a los más recientes Estatutos de Autonomía.

El profesor Martín Rebollo se extrañaba de que la propiedad tuviera categoría de derecho fundamental y no la tuviera en cambio la respon- 
sabilidad patrimonial de la Administración, de significado tan similar. La responsabilidad extracontractual venía estando en los Tratados, hoy, en el artículo 340 del TFUE. Pues bien, es curioso comprobar que hoy, como ya he señalado en alguna otra ocasión, el derecho a la reparación de los daños causados se ha codificado en el apartado tercero del citado artículo 41 de la Carta, con lo que pasa a adquirir el rango de derecho fundamental.

b) Ya estaba en el Tratado Constitutivo de la Comunidad Económica Europea, y había sido objeto también de la directiva correspondiente, lo referente al tratamiento de datos personales, que hoy figura en los artículos 16 del TFUE y 39 del TUE. La Carta lo codificó, llevándolo al artículo 8 , dándole además tratamiento de derecho fundamental autónomo: «Toda persona tiene derecho a la protección de los datos de carácter personal que le conciernan». El derecho comunitario sirvió de acicate para que fuera recibido ampliamente en España, contando además con que no estaba recogido de forma expresa en la Constitución (en general, se ha hecho derivar del artículo 18 con su protección de la intimidad). Es indudable que hoy ha alcanzado un desarrollo considerable en nuestro sistema jurídico, aunque se trate de materia ardua y dura de implantar, que incide además sobre tan diferentes sectores. Por supuesto, en cuanto al aspecto organizativo, se ha recogido también el criterio comunitario, del apartado 3 del artículo 8 de la Carta, que viene también de los Tratados, de que sea una autoridad independiente quien se encargue del control de tan importante como delicada materia.

c) En relación con el derecho de propiedad, el artículo 17 de la Carta recoge, modernizando, lo que había consagrado en numerosas ocasiones el Tribunal de Justicia, en línea, por otra parte, con lo que es común en las Constituciones de los Estados miembros. Pero incorpora una matización interesante cuando afirma: «Toda persona tiene derecho a disfrutar de la propiedad de los bienes que haya adquirido legalmente...». Se atiende así a una necesidad imperiosa para el correcto funcionamiento de los derechos fundamentales en una sociedad tan compleja como la presente, tan rica en intercambios y relaciones a consecuencia de la facilidad de viajes y comunicaciones, en suma, las consecuencias de la globalización. Los derechos fundamentales se sitúan en la cumbre de los ordenamientos, como se decía, pero es obvio que no vale cualquier cosa. Antes se transcribían los valores que fundamentan a la Unión Europea, tal y como los enuncia, por ejemplo, el artículo 2 TUE. Importa sobremanera el Estado de derecho y el afianzamiento de una sociedad 
basada en la legalidad. Pues bien, en medio de los ciudadanos que conviven con toda normalidad en el respeto a la ley, no se puede olvidar la existencia de personas o de organizaciones muy sofisticadas que hacen del lucro ilícito su medio de enriquecimiento. Hizo su aparición la lacra de lo que se denomina vulgarmente «blanqueo de dinero», relacionado normalmente con acciones profundamente antisociales, como puedan ser las relativas al mundo de las drogas, contrabando, trata de personas, corrupción, etc. Y es lógico que se tome partido contra ello. De modo que no se protegerá cualquier propiedad. Es así como se ha originado un entramado de normas con sus exigencias para tratar de prevenir o, al menos, dificultar tales actividades. La Unión Europea ha sido muy activa a la hora de tomar medidas, de manera muy señalada en todo lo que se refiere a actividades bancarias y a cualquier otra forma de traslado de capitales. Incluso, y no deja de ser curioso y creo que sorprendente, ello ha conducido a la práctica proscripción de los billetes de cuantía elevada, como sucede con los de quinientos euros. Medidas que obviamente han debido ser recibidas y complementadas por los Estados miembros, lo que ha sucedido por supuesto en España, y que muchas veces resultan un auténtico engorro para los ciudadanos normales que actúan dentro de la legalidad, pero que se consideran necesarias para evitar males mayores. De modo que tras este destacado «matiz» de la Unión Europea, el derecho de propiedad ha asumido tan cualificada connotación.

d)-No dejaré de llamar la atención sobre el artículo 3 de la Carta, que además de consagrar la clásica regla del derecho a la integridad física y psíquica de las personas, incluye disposiciones novedosas en una declaración de derechos, «en el marco de la medicina y la biología», que obviamente proyectan su incidencia sobre el derecho español y que de hecho han predeterminado intensamente nuestra forma de proceder. Las "explicaciones» aclaran al respecto que en una sentencia de 9 de enero de 2001, el Tribunal de Justicia puntualizó - Asunto Países Bajos contra Parlamento Europeo y Consejo- que en el derecho a la integridad de la persona se incluye, "en el ámbito de la medicina y de la biología, el consentimiento prestado libremente y con conocimiento de causa por el donante y el receptor».

Destacada es también la formulación expresa de «la prohibición de las prácticas eugenésicas, en particular las que tienen como finalidad la selección de personas» (3.1.b). Con lo que se llevan a la declaración de derechos los criterios del Estatuto de la Corte Penal Internacional, tan frescos en la memoria los horrores de la política de selección que 
practicaron algunos Estados en el periodo anterior a la Segunda Guerra Mundial, pero como aviso, también, para cualquier aventurero que quisiera dárselas de innovador científico en tan delicado campo. Se prohíbe igualmente «la clonación reproductora de seres humanos» (3.1.d). Las "explicaciones» aclaran que la regla se atiene estrictamente a las previsiones del Convenio del Consejo de Europa relativo a los derechos humanos y la biomedicina, y por tanto ni autoriza ni prohíbe otras formas de clonación, ámbito en el que se mantiene la opción de los Estados para actuar en un sentido u otro.

De destacar también «la prohibición de que el cuerpo humano o partes del mismo en cuanto tales se conviertan en objeto de lucro» (3.1.c), ya existente en nuestro derecho desde que se hizo la Ley de Trasplantes así como en el ámbito de la donación de sangre, pero refuerzo y recordatorio útil, pues nunca se sabe lo que puede suceder, dado que en este mundo hay voluntarios para todo, a la vista también de las lamentables circunstancias que imperan en algunos países en los que se autoriza el inmisericorde comercio de órganos del cuerpo humano.

12.- Para ir concluyendo me centraré someramente en algunos supuestos - de los muchos existentes-, en que se advierte con claridad cómo el derecho europeo ha incidido sobre nuestro sistema de derechos fundamentales.

En la Constitución española, al proclamarse los derechos y libertades fundamentales, se suelen usar fórmulas genéricas para aludir a los titulares — «toda persona», «todos», «se garantiza», o, en formulación negativa, "nadie puede ser condenado»-, pero también encontramos reiterada la fórmula de que el ejercicio de algunos derechos está contemplado específicamente para «los españoles». Así, por ejemplo, «Los españoles tienen derecho a elegir su residencia» (artículo 19), y lo mismo se diga del derecho de petición (artículo 29), del derecho de sufragio para las elecciones municipales (artículo 13.2), del derecho al trabajo (artículo 35), o de la no discriminación (artículo 14). Pues bien, la entrada en vigor del Tratado que hace treinta años, como ahora estamos celebrando, habilitó el ingreso de España en la Comunidad Económica Europea, implicó el significativo cambio de que todas esas opciones quedaran abiertas también para los ciudadanos comunitarios. Curiosamente, salvo en lo referente a la opción de poder ser elegidos en las elecciones locales, es decir, el derecho de sufragio pasivo, que, como dije, sí se modificó el texto, en los demás casos no se estimó necesario reformar la Constitución y se dio por buena una simple interpretación ampliatoria. Es decir, que la presencia del derecho comunitario implicó una notable alteración-ampliación a la hora de la aplicación de nuestro 
sistema de derechos. No se alteró, por razones obvias, lo referente a la participación política, previsto específicamente para los ciudadanos, cuando el artículo 23.1 dispone que: «Los ciudadanos tienen el derecho a participar en los asuntos públicos, directamente o por medio de representantes, libremente elegidos en elecciones periódicas por sufragio universal». Es lógico que este núcleo de la gestión de lo público se reserve a los nacionales.

En cambio, el contenido del apartado segundo del precepto, referido a lo que genéricamente designamos como la función pública, previsto inicialmente también para los ciudadanos, experimenta una notable ampliación debido al derecho comunitario - hay una temprana ley de adaptación de 1993, puesta al día en diversas ocasiones-, de modo que se puede decir que casi prácticamente se da la vuelta al sistema, por lo que el principio pasa a ser el que los ciudadanos comunitarios podrán acceder a los empleos públicos salvo las excepciones que estén expresamente enumeradas.

13.- Por cierto que en lo que concierne al referido derecho de participación política, del artículo 23.1, hay que decir que la jurisprudencia del Tribunal Europeo de Derechos Humanos ha dado un salto sorprendente, propiciando una muy destacada ampliación, como he tenido ocasión de estudiar recientemente -interpretación que en algún caso no ha dejado de levantar grandes reticencias en el Reino Unido-, al dar aplicación al artículo 3 del Protocolo Adicional Primero, que prevé la celebración de elecciones libres «en condiciones que garanticen la libre expresión de la opinión del pueblo en la elección del cuerpo legislativo». Jurisprudencia, claramente ampliatoria, que, sin embargo, sirve para matizar y condenar supuestos que suponían una clara extralimitación de las posibilidades. Siendo de destacar así, en relación con España, una serie de sentencias que desactivaron radicalmente la presencia de partidos y coaliciones electorales que no respetaban las reglas democráticas. En un pequeño libro, yo mismo analizaba hace un par de años «la doctrina del Tribunal sobre el entorno de ETA», que, ante todo, avalaba la legitimidad de la tan oportuna como acertada Ley de Partidos Políticos, la orgánica 6/2002, de 27 de junio, que prohibía el paso a los partidos con métodos u objetivos antidemocráticos. Recordaré sólo, a modo de ejemplo, las sentencias «Herri Batasuna y Batasuna c. España», 30.VI.2009, y «Acción Nacionalista Vasca c. España», 7.XII.2012, que resultaron concluyentes para sanear el panorama político español, pero que obviamente sirvieron de aviso para cualquier pretensión de alcance similar que pudiera aparecer en el panorama europeo. Ello, insisto, dentro de una línea de claro potenciamiento de los partidos políticos y de la actividad política en general. 
14.- El anterior ejemplo evidencia el repudio inequívoco del Tribunal para con las tácticas etarras. Pero está claro que el Tribunal Europeo dice lo que tiene que decir en cada ocasión, en su labor de dar aplicación objetiva al Convenio Europeo, pese a quien pese y aunque a veces pueda parecer sorprendente. Digo esto dado que su labor consiste en resolver en derecho, labor en la que obviamente no se puede contentar a todos. Y es que causó en España una profunda sensación una sentencia que afectaba directamente a una etarra condenada por muy numerosos crímenes, no pocos de los cuales habían supuesto la muerte de la víctima. Se trata de la Sentencia Del Río Prada c. España, de 12 de julio de 2012, en la versión de la Sala, y de 21 de octubre de 2013, cuando la Gran Sala resolvió el correspondiente recurso. Estaba en juego el principio de legalidad penal, el problema de la retroactividad, así como el derecho a no ser privado de libertad en principio sin la correspondiente decisión judicial. No me detendré en el caso, al que he dedicado atención recientemente en otro lugar. Se trata de un complejo asunto en el que se discutía cómo había de realizarse el cómputo para la aplicación de las penas. Pues bien, el Tribunal Europeo, con toda corrección en mi modesta opinión, coincidiendo con un significativo voto particular que se formuló en el Tribunal Supremo cuando conoció del asunto, entendió que España había dado incorrecta aplicación retroactiva a una fórmula de cómputo de las penas, que implicaba alargar indebidamente el periodo de privación de libertad, lo que hizo que la recurrente viera prolongada su detención sin justificación legal para ello. El Tribunal condenó a España, ordenó la inmediata puesta en libertad de la recurrente y le otorgó una significativa indemnización por la incorrecta privación de libertad. Con la particularidad de que sentencia tan terminante y clara no sólo afectaba a la recurrente en el caso, sino que iba a proyectarse a un destacado número de etarras que se encontraban en la misma situación, y a otros significados delincuentes. La sentencia sorprendió por sus efectos, dada la inmediata liberación de personas autoras de graves conductas antisociales, e, incluso, provocó una histérica reacción, sobre todo en políticos que habían prometido lo que no podían prometer. Pero la sentencia era correcta y no queda más remedio que reconocer que España no había hecho bien las cosas, que el legislador no había actuado cuando debiera haberlo hecho.

15.- En un orden de cosas muy diferente, quiero concluir la referencia a la jurisprudencia del Tribunal de Derechos Humanos aludiendo a una interpretación muy sugestiva, muy eficaz a la hora de proyectar destacados efectos positivos en la aplicación de los derechos humanos. El artículo 18.2 de la Constitución española garantiza la defensa del do- 
micilio, precepto equivalente a lo que significa el artículo 8 del Convenio Europeo. Se venía entendiendo tradicionalmente que el domicilio se violaba a través de la intrusión ilegítima de personas: el ladrón, o incluso el funcionario que no contara con el necesario mandato judicial. Pero se cayó en la cuenta de lo fácil que es en nuestra civilización que el domicilio sea gravemente perturbado a través de olores, humos o sonidos agresivos. Y el Tribunal aceptó de lleno esta doctrina, aplicándola en casos muy significativos que no es éste el momento de exponer. Se proporcionaba así un arma contundente a la hora de defenderse, por ejemplo, frente a la lacra del ruido, auténtica asignatura pendiente en España como es bien sabido. Así, la doctrina del Tribunal ha puesto las bases para que se iniciara una cierta sensibilización social, primer paso para avanzar en la resolución del problema, así como a que se activara una cierta reacción de las instituciones, aunque sin que pueda llegarse a cantar victoria.

16.- No entraré en más detalles, dado que se trataba sólo de exponer una visión de conjunto. Por supuesto que la influencia del derecho de la Unión Europea ha contribuido a potenciar e incrementar en nuestro sistema la garantía de muchos otros derechos fundamentales. Muy notable es lo que ha representado para la libertad de empresa, para abrir de par en par las puertas de la contratación con el sector público, o, en relación con la libertad de expresión, lo que ha significado el romper los monopolios a propósito de la telefonía, la radiodifusión y de la televisión, con todas las variedades de la transmisión de mensajes. Pero es que el fenómeno se observa en los aspectos más insólitos o insospechados, que a veces habría que hacérselos presentes a quienes desprecian la organización europea: en efecto, recordaré, para terminar, lo que vino a significar en un campo que suscita tantos entusiasmos e interesa a tantísima gente, como el del fútbol, la famosa Sentencia Bosman, abriendo la puerta a la entrada de jugadores de otros países. Estoy seguro que los aficionados no entenderían que las cosas no fueran así.

En suma, treinta años muy fructíferos, de intenso potenciamiento de las oportunidades de los derechos fundamentales. La «interconexión de ordenamientos jurídicos», el influjo tanto de la jurisprudencia del Tribunal Europeo de Derechos Humanos, sobre todo al inicio, como, después, el del derecho de la Unión Europea en sus más variadas fórmulas, han producido muy positivos efectos en el campo de los derechos humanos, con la particularidad de que se trata de un proceso abierto, que no se detiene, en el que además son tantos los interesados en que se avance y en el que hay tantos ojos vigilantes. 